\title{
Assisted Fertility in Complete Paraplegia: Case Report
}

\author{
H. Rawicki, ${ }^{1,2}$ D. W. Lording ${ }^{3}$ \\ ${ }^{1}$ Caulfield Rehabilitation Hospital, 294 Kooyong Road, Caulfield, 3162, \\ Australia. ${ }^{2}$ Royal Talbot General Rehabilitation Hospital, Yarra Boulevard, \\ KEW 3101, Australia. ${ }^{3}$ Alfred Hospital, Melbourne, Australia.
}

\begin{abstract}
Summary
A 34-year-old paraplegic man with a spinal cord injury complete below the 6th thoracic segment fathered a child by artificial insemination using semen obtained by electro-ejaculation. A long fertility programme culminated in the delivery of a healthy male child weighing $3665 \mathrm{~g}$ in April 1987. Guidelines for a comprehensive fertility programme are discussed briefly.
\end{abstract}

Key words: Paraplegia; Electro-ejaculation; Fertility; Artificial insemination.

Fertility in men with complete spinal cord injury has been infrequently reported. Until the early 1980s, it had been generally accepted that only about $1^{\circ}{ }_{0}$ of affected men could father a child (David et al., 1977; Amelar et al., 1982; Otani et al., 1985). Collated reports indicate that unassisted ejaculation or emission of semen occurs in up to $14^{\circ}$ of men with complete spinal cord injury (Madduri et al., 1979; Amelar et al., 1982; Otani et al., 1985). Such semen as is obtained has almost invariably shown very low sperm motility; usually $0-5 \%$ (Guttmann and Walsh, 1971; Amelar et al., 1982; Brindley, 1984). Sperm morphology often shows an increase in abnormal forms and, less frequently, counts may be subnormal. There have been three main ways of improving the rate of semen collection. They are:

1. Anticholinesterases. Intrathecal prostigmine was first used by Guttmann and Walsh in 1971. This produced good ejaculation of semen but is now used only infrequently due to the serious and occasional fatal reactions that occurred with its use. However, there has been a recent Japanese report of a pregnancy following use of this method (Otani et al., 1987).

Subcutaneous physostigmine masturbation has been used by Chapelle et

Correspondence to: Dr H. B. Rawicki, Caulfield Hospital, 294 Kooyong Road, Caulfield, 3162, Australia. 
al., and he has recently reported ejaculation in 75 of 135 patients, 15 of whom fathered children (Chapelle et al., 1988).

2. Electro-ejaculation was first reported in 1948 (Horne et al.). The first pregnancy reported using electro-ejaculation followed by artificial insemination of the husband's semen occurred in Melbourne in 1975 (Thomas et al., 1975). Unfortunately the baby was born with transposition of the great vessels and died 24 hours after birth. The first successful pregnancy using this method occurred in 1976 (Francois et al.). This method has been used more frequently in the last decade and Brindley in particular has reported a number of pregnancies (Brindley, 1984, 1981a, 1981b).

3. Vibrators have been applied to the base or the frenulum of the penis to stimulate ejaculation or emission of semen. Brindley (1981) and others (e.g. Szasz, 1987) have achieved consistent success in obtaining semen using this method and a number of pregnancies have been subsequently reported.

The poor quality of the semen obtained by all these methods has been attributed to a number of factors (Brindley, 1982, 1984). These include elevated testicular temperatures, frequent urinary and genital tract infections and low semen turnover. There is some dispute over baseline serum levels of follicle stimulating hormone $(\mathrm{FSH})$, luteinising hormone $(\mathrm{LH})$, testosterone and prolactin, with some authors finding these to be within normal limits (Madduri et al., 1979; Naftchi et al., 1980; Young et al., 1982), others finding elevated $\mathrm{FSH}, \mathrm{LH}$ and Prolactin and low testosterone (Cortes-Gallegos et al., 1981; Hayes et al., 1979). Others have found an elevated LH and testosterone (Perkash, et al., 1985) and one author has found differences between men with upper motor neuron and lower motor neuron injuries (Nance et al., 1985).

Despite the fact that it is possible to collect semen from increasing numbers of men with spinal cord injuries, until the end of 1986 only 9 pregnancies had been reported in the literature (Thomas et al., 1975; Francois et al., 1978; Brindley, 1981; Otani et al., 1985). This report therefore adds a further case to the small but increasing number of successful interventions in this group.

\section{Case report}

The patient was a 34-year-old male who became a complete T6 paraplegic following removal of a spinal ependymoma in 1978 . He has spastic paraplegia, is on no medications, has never had a sphincterotomy and has had only infrequent urinary tract infections. He manages his bladder with a combination of automatic micturition and stimulated reflex emptying and uses an external urinary collecting system. He had not ejaculated since his spinal cord lesion despite the use of a vibrator. He married after his spinal cord injury. His wife was a healthy 29 -year-old nulliparous woman with no history of gynaecological disease.

At the commencement of the programme, the patient had baseline hormonal assays comprising prolactin, testosterone, $\mathrm{FSH}$ and $\mathrm{LH}$, all of which were within normal limits for an adult male. An electro-ejaculation programme was begin in 1984 using a purposebuilt electrical stimulator and rectal probe. The stimulator is powered by a portable $12 \mathrm{~V}$ battery. It delivers a sine wave current with a maximum amplitude of 30 volts. The current frequency is adjustable but best results, including for this patient, are obtained with 10 Herz. Weekly ejaculations were performed along with regular seminal analyses. 
Over the course of these analyses, semen volumes, with one exception, were always between 1.5 and $4.0 \mathrm{ml}$. Sperm counts were between 50 and $300 \times 10$ per ml. Sperm motility, however, for the first 8 months of the programme varied between $2 \%$ and $5 \%$. Following this, sperm motility increased, such that in March 1985 it was $8 \%$ and in June $1985,15 \%$. Following the cessation of the programme in July 1985, coinciding with the first pregnancy, sperm motility again dropped to $2 \%$ in September 1985. In December 1985 , motility was $20 \%$ and in June $1986,18 \%$. Following the second pregnancy when the programme was resumed in June 1987, sperm motility was again 3\%. Advice was given on an empirical basis to assist in lowering testicular temperatures; in particular the patient was advised to sit with his legs apart; he embarked upon a regular 3-4 times weekly swimming programme and redesigned his cushion to an anterior wedge shape to allow air to circulate more freely to the scrotal area. He almost always wore cotton jeans and did not wear underpants.

The patient's wife had hormonal assays comprising $\mathrm{FSH}, \mathrm{LH}$, prolactin, thyroid function tests (TFT's) and a modluteal progesterone. In addition to this she also underwent a hysterosalpingogram and laparoscopy. All these tests were normal. To assist in the timing of artificial insemination by her husband and to ensure that she was ovulating, she was placed on a regime of Clomiphene $50 \mathrm{mg} /$ day on days 5-9 of her cycle (day 1 being the first full day of menstrual bleeding) followed by 5000 units of human chorionic gonadotrophin (HCG) intramuscularly on day 14. In July 1985, she became pregnant but the pregnancy ended in a spontaneous abortion at 8 weeks. Two months later, the programme was reinstituted and she became pregnant again in July 1986 . This pregnancy proceeded to term and she gave birth to a healthy baby boy weighing $3665 \mathrm{~g}$ on 13 April 1987.

The couple have now re-entered the programme with a view to achieving a further pregnancy.

\section{Discussion}

A fertility programme for men with spinal cord injury was commenced in 1984 . Twenty patients and their partners have been assessed for the programme. Their spinal cord lesions have been both complete and incomplete and have ranged from C5 quadriplegia to T12 paraplegia.

Electro-ejaculation has led to consistent semen emission in 12 men. Two men have had consistent successes using the vibrator and another had inconsistent successes. One man in whom electro-ejaculation failed has subsequently been able to collect semen by masturbation and his wife is now pregnant. At least 2 patients have had retrograde ejaculation using electro-ejaculation and this has probably been the cause of some of the other failures. This has been only looked for in the last year of the programme.

One patient, an incomplete quadriplegic below $\mathrm{C} 6$, had electro-ejaculation performed with success under general anaesthesia. By contract, another patient, not included in the 20, neurologically normal but suffering from impotence secondary to long term alcohol abuse, had electro-ejaculation under general anaesthesia without success.

The authors work with both partners in all cases. When appropriate, the partners are prescribed Clomiphene and HCG as described in the case report (vide supra) in order to facilitate the timing of insemination and to ensure ovulation.

Regular electro-ejaculation has been associated with normal sperm counts in most cases and both in our experience and in the experience of others (Brindley, 1984; Otani et al., 1985), there have been increasing sperm motility and de- 
creasing numbers of abnormal forms with repeated ejaculation. We are thus optimistic that fertility rates can be improved if those taking part in the programme, patients, partners and medical staff, are prepared to persist for periods for as long as 1-2 years. A major ongoing challenge is to improve the fertility of semen collected from men with spinal cord injury. Improved pregnancy rates may then be expected to occur.

Though it is obvious that more research needs to be done in this area, the future possibilities are not so bleak as have been previously portrayed.

\section{References}

AMELAR RD, et al. 1982 Sexual function and fertility in paraplegic males. Urology XX(1):62-65.

BRINDLEY GS 1981a Reflex ejaculation under vibratory stimulation in paraplegic men. Paraplegia 19(5):299-302.

BRINDLEY GS 1981b Electro-ejaculation. Its technique, neurological implications and uses. fournal of Neurology, Neurosurgery and Psychiatry 44:9-18.

BRINDLEY GS 1982 Deep scrotal temperature. British fournal of Urology 54(1):49-55.

BRINDley GS 1984 The fertility of men with spinal injuries. Paraplegia 22:337-348.

ChaPelle PA, et al. 1988 Neurological correlations of ejaculation and testicular size in men with a complete spinal cord section. Fournal of Neurology, Neurosurgery and Psychiatry 51:197-202.

Cortes-Gallegos V, et al. 1981 Pituitary-testis relationships in paraplegic men. American Society of Andrology 2:326-330.

David A, et al. 1977 Spinal cord injuries. Male Infertility Aspects. Paraplegia 15(1):11-14.

FRANCOIS N, et al. 1978 Electro-ejaculation of the complete paraplegic followed by pregnancy. Paraplegia 16:248-251.

GuttMann L, Walsh JJ 1971 Prostigmine assessment test of fertility in spinal man. Paraplegia 9:39-50.

HAYES PJ, et al. 1979 Testicular endocrine function in paraplegic men. Clinical Endocrinology 11:549-552.

HORNE HW, et al. 1948 Fertility studies in human male with traumatic injuries to the spinal cord and cauda equina. New England fournal of Medicine 239:959-961.

MADDURI, et al. 1979 Plasma androgens and estrogens in paraplegic men. Urology 13(2):179-181.

NANCE PW, et al. 1985 Gonadal regulation in men with flaccid paraplegia. Archives of Physical Medicine and Rehabilitation 66:157-159.

NafTCHI NE, et al. 1980 Pituitary testicular axis dysfunction in spinal cord injury. Archives of Physical Medicine and Rehabilitation 16:402-405.

OTANI, et al. 1985 A paraplegic fathering a child after an intrathecal injection of neostigmine: Case Report. Paraplegia 23:32-37.

PERKASH I, et al. 1985 Reproductive biology of paraplegics. Fournal of Urology 134:284-288.

SzASZ G 1987 Vibratory stimulation of the penis in men with spinal cord injuries. Paraplegia 25:60 (Abstract).

Thомаs RJS, et al. 1975 Electro-ejaculation of the paraplegic male followed by pregnancy. Medical Fournal of Australia 2:798-791.

YouNG RJS, et al. 1982 Is testicular endocrine function abnormal in young men with spinal cord injuries? Clinical Endocrinology 17:303-306. 